TITLE: MICROWAVE ASSISTED CHEMICAL VAPOR INFILTRATION

This report was prepared as an account of work sponmored by an agency of the Uniled Siates Government Neither the IJnited Situtes Ciovernment nor uny agency thereof. nor any of iheir employees. makes any wapranly, express of implied, or assumes any legal liubilily or responability for the accuracy. completeness, or usefulness of uny information, apparalus. product, or procens disclined, or represents that its uxe would not infringe privately owned rights Refer. ence herein to any specific commercial product, pricesa, of service hy trade name. Irademurh. manufecturer, of otherwise doss not necessarily conslitule or imply is eidorsement, ecom. mendation, if favoring hy the l!nited Slates Government or any agency thereat The views and opinions of authofs expressed herein do not necensarily state of reflect thine of the United Sisten (bovernment or any agency thereor.

$\left[\prod_{-\infty}\left(l_{0}\right)(3)\right.$

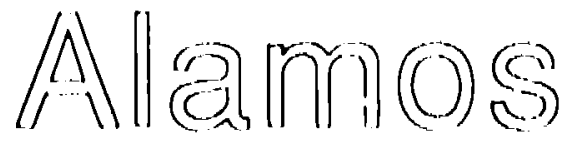
Los Alamos National Laboratory
Los Alamos, New Mexico 87545 FOnMNO MS IM Si No 7020 MOt

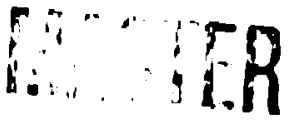




\title{
MICROWAVE ASSISTED CHEMICAL VAPOR INFILTRATION
}

\author{
D.J. Devlin, R.P. Currier, R.S. Barbero, B.F. Espinoza, and N. Elliott \\ Materials Science and Technology Division \\ Los Alamos National Laboratory \\ Los Alamos, NM 87545
}

\begin{abstract}
A microwave assisted process for production of continuous fiber reinforced ceramic matrix composites is described. A simple apparatus combining a chemical vapor infiltration reactor with a conventional $700 \mathrm{~W}$ multimode oven is described. Microwave induced invented thermal gradients are exploited with the ultimate goal of reducing processing times on complex shapes. Thermal gradients in stacks of $\mathrm{SiC}$ (Nicalon) cloths have been measured using optical thermoliietry. Initial results on the "inside out" deposition of $\mathrm{SiC}$ via decomposition of methyltrichlorosilane in hydrogen are presented. Several key processing issues are identified and discussed.
\end{abstract}

\section{INTRODUCTION}

Many materials used in high temperature service, including monolithic ceramics, tend to be brittle and susceptible to catastrophic failure through crack propagation. This has lead to concentrated interest in the fabrication of fiber reinforced ceramic matrix composites (CMCs). CMCs consist of a fibrous backbone, or substrate, whose void spaces are filled with a "matrix" material. The chemical composition of the matrix may or may not be the same as thai of the fibers. While a random pile of individual fibers may be used as reinforcement, the tougher CMCs typically consist of continuous fiber bundles, or yarn, woven together to form either two or three dimensional "textile" cloths.

Processing techniques for CMCs differ primarily in the way matrix materials are infiltrated into the porous substrate. Infiltration may involve molten liquids, sol-gels, polymeric materials, powders, or vapors. Most of these techniques require final densification steps, e.g. sintering, involving matrix shrinkage. Large residual stresses can develop when a matrix shrinks around non-shrinking fibers. Chemical vapor infiltration (CVI) is an attractive altemative for matrix deposition since it avoids stressing the fibrous backbone during processing. Also, relatively low temperutures are used in CVI which limits adverse chemical attack on the fibers. Conventional CVI processes may be either isothermal or involve intentionally imposed thermal gradients. Deposition may be reaction or diffusion limited, or may rely on forced and/or pulsed reactant f $\partial w s$. 'The various configurations have recently been reviewed by Besmann et al $|1|$. To varying degices. conventional CVI processes are typically subject to some or all of the following drawbacks: preferential depesition in the substrate's outer regions leading to pore blockuge; Iong processing times with intermittent machining operations: non-uniform composite density; high residual porosity; and limitutions on substrate geometry. However, despite inherent limitations commercial CVI operations ure now in place.

The ideu of using electromagnetic radiation, in particular microwaves, to heal substrutes during CVI has recently been explored numerically $|2|$. The potentiul advuntuge in using microwuve heating is the ubility 'o heat the substrate intermully, giving rise is "inverted" thenmul grudients. With the internal region of the substrute $h(t), c(x) l$ reactunt guses could penetrate inwird prior to the onset of reaction. Conseyuently, deposition could (xecur from the inside-(out. A successful microwave CVI proxess could offer several advantages over conventional technologies. lïrst, constraints on substrate geometry would be removel. Second, more sputially uniform, high

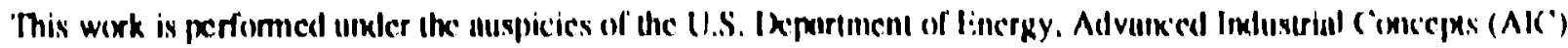
Mutcriuls Prongrum. 
density composites should be attainable. Third, relatively shor processing times should be possible. Fourth, machining operations to reopen closed pores should not be necessary since densification would occur from the inside-out. Success will of course require proper management of heating and cooling rates. The electric field within the preform govems the local heating rate. Interaction of an electromagnetic field with a porous preform is complicated. In general, the local heating rate is proportional to the square of the electric field strength and to the effective dielectric constanı and loss factors for the growing composite. On the other hand, substrate heat losses occur primarily by way of radiation and convection. One expects these losses to depend on geometry, temperature, flow rates, and to a lesser ex:ent, on weave architecture and lay-up pattem. The present work is an experimental investigation into the feasibility of microwave assisted CVI. Emphasis is on quantifying induced thermal gridients, combining CVI and microwave heating to demonstrate inside-out densification, and examınation of materials and processing issues.

\section{EXPERIMENTAL RESULTS}

In order to quantify the microwave induced thermal gradients, optical thermometry experiments were conducted. Measurements were made in cylindrical SiC cloth lay-ups subject to $7(X) \mathrm{W}$ of $2.45 \mathrm{GHz}$ mictowave energy. Measurements ware conducted in a commercial General Electric multimode oven. Temperatures were measured along both the cylinder axis and mid-plane radius using quarz fiber optic cables woven directly into the substrate. The optical cables were connected via photodiodes to amplitier circuits from which voltages were read. Each optical thermometer was first calibrated using stacks of $\mathrm{SiC}$ cloth placed in a conventional high temperature furnace. The thermal profiling data shown in Figure 1 incicates that steep inverted thermal gradients can be established in SiC cloth lay-ups.
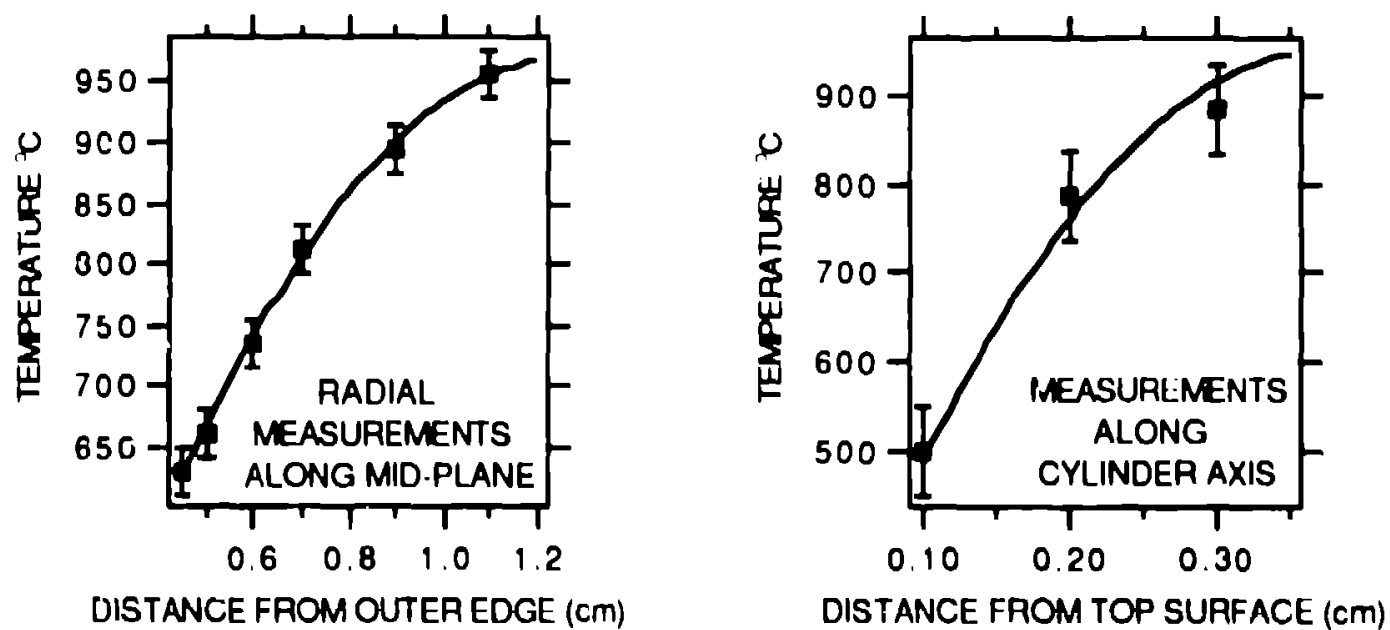

EGURE_. Invered thennal gradients in SiC cloth lity-ups.

Internal temperatures in excess of I KXXYC. were observed in stagnant air along with gradients on the order of severul hundred "C/cm. Similar gradients are seen in atmospheres other than air, e.g. $\mathrm{H}_{2},\left(\mathrm{I} \mathrm{I}_{\mathrm{A}}\right.$, and $\mathrm{C}, \mathrm{H}_{\mathrm{h}}$. The error bars shown in the figures include contributions from positioning ciables within the preform und vuriations in the voluge rendings, us deduced from the culibrution

ligere 2 is a schematic of the gas delivery system and micrownve CVI cinvity. "The latter consisted of a modified 2.4.5 (il 1\%. 7(x) W (ieneral filectric commercial multimoxle oven. A circular liole was laser cul through the oven flexor through which a Pyrex bell jar reaclor was inserted. 'The interios !(x)r of the reaction vessel wils a metallic plate with a circular hole in the center useal for reactant feed and proxluct gas removal. $\wedge$ metallic sleeve was utilized lo reseal the cavity. 

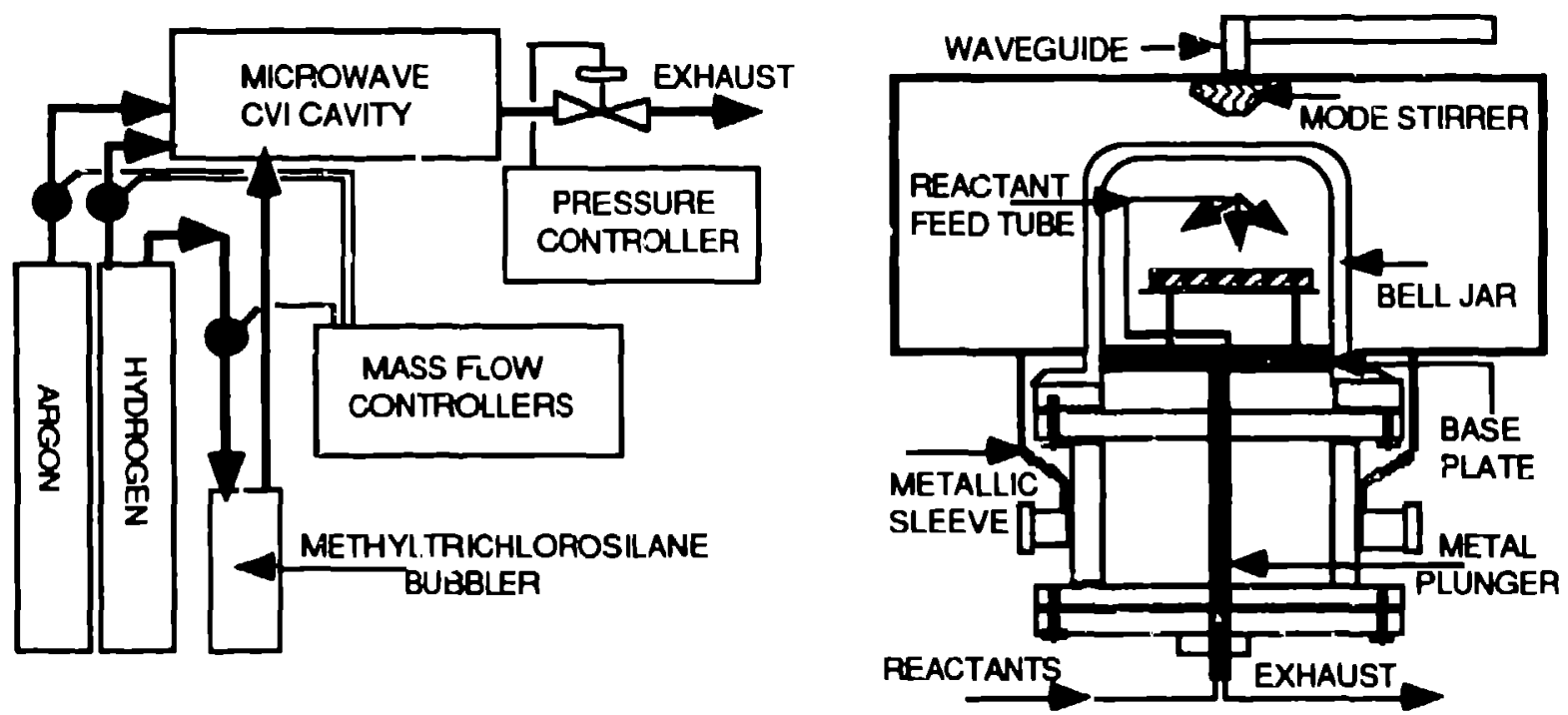

FIGURE 2. Microwave EVI Apparatus.

Provisions were made for sampling of reactant and exhaust gases for analysis by FTIR and mass spectroscopy. Substrates consisted of a pile of ten circular Nicalon (SiC) cloth sections with a $7 \mathrm{~cm}$ diameter. A quartz ring $2.5 \mathrm{~cm}$ high was used to positioned these off the reactor flour. Initial experiments involved deposition of $\mathrm{SiC}$ from methyltrichlorosilane (MTS) and hydrugen through the reaction $\mathrm{CH}_{3} \mathrm{SiCl}_{3}+\mathrm{H}_{2}=\mathrm{SiC}+3 \mathrm{HCl}$. Two sets of -eaction conditions were considered:

\begin{tabular}{ccccccc} 
Case & Total Pressure & \multicolumn{2}{c}{ Partial Pressure MTS } & Hydrogen Flow & Rale (mg/min) \\
I & $3(0)$ & Tort & 1 & Tor & $4000 \mathrm{sccm}$ & $\approx 0.5$ \\
II & 600 Tor & 20 Torr & $500 \mathrm{sccm}$ & $\approx 7.0$
\end{tabular}

These infiltration conditions were chosen to represent both low and high SiC deposition rates.

Figure 3 shows photographs of cloth layers from the stack center under Case I conditions.

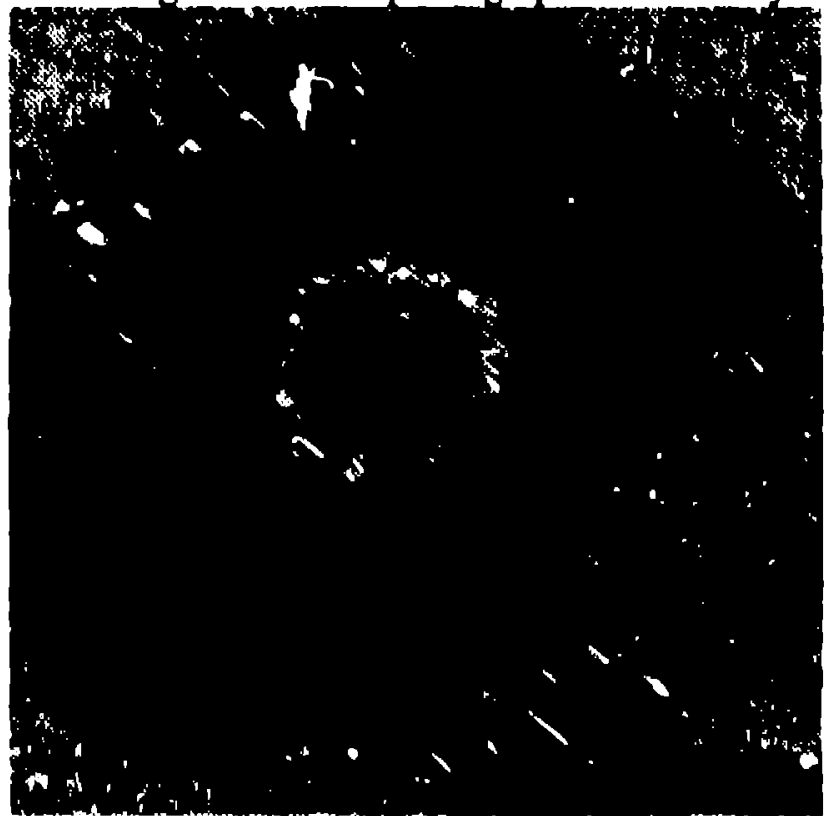

(a)

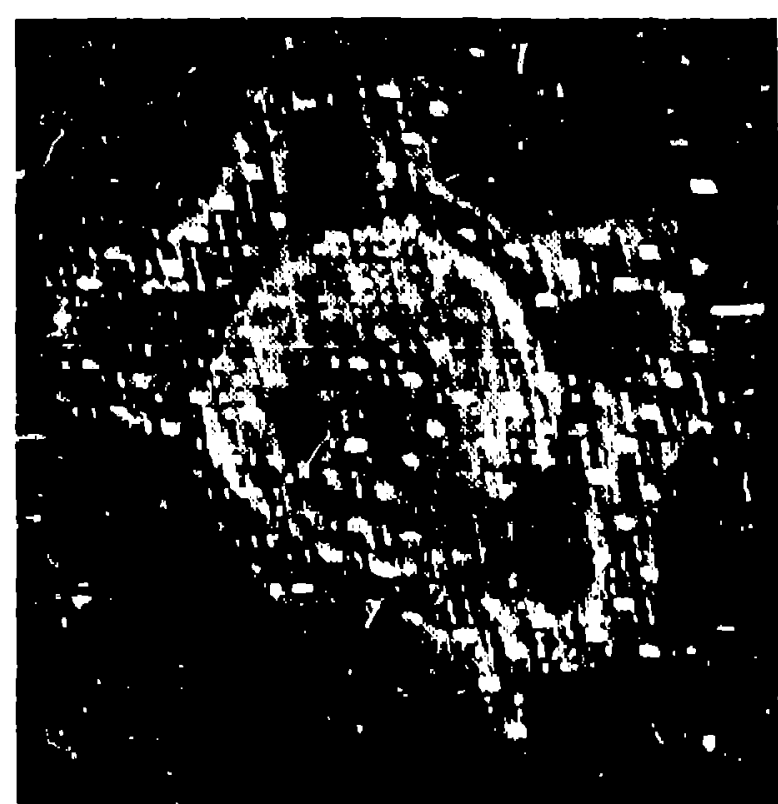

(b)

EUCL BE 1. Partiully densified cloth. (a) Inside-out densification. (h) Nonuniform heating paltern. 
With radiation and convective heat losses at the surface, the highest temperatures were at the preform center. CVI against the thermal gradient resulted in preferential deposition in the hot region. The coated region, which appears white, is clearly seen in Figure 3(a) The size of this infiltrated region decreases in diameter moving along the stack axis toward either the top or bottom surface in general agreement with the thermal piofile data shown in Figure 1. However, with the longer infiltration times the substrate center appeared to cool and patterns such as that seen in Figure 3(b) typically evolved. Several factors may contribute to this phenomenon. First, regions may be selectively cooled by reactant gas flow patterns. If this is the case, then a systematic study using various cloth lay-up patterns, weave architectures, and gas dilivery configurations is called for. However, initial experiments do not suggest a strong sensitivity to lay-up pattem or gas flow rate. Another possible factor contributing to inhomogeneous heating patterns is that the microwave cavity employed in these experiments is less-than-perfect. It is widely known that commerciai multimode ovens of these dimensions do not heat uniformly. A related issue is that as densification occurs it may be necessary to continuously increase the misrowave power input above the currently available $700 \mathrm{~W}$ to maintain the desired heating rate. A more robust microwave CVI reactor should eliminate these difficulties. Finally, the possibility that the deposit affects microwave susceptibility must be considered. If filaments are coated with a material which does not couple well with the electric field to produce heating, then the heating rate inay diminish once the coating thickness exceeds the skin penetration depth:

$$
\text { Skin depth }=1 /(\pi f \mu \sigma)^{1 / 2}
$$

where $f$ the frequency, $\mu$ is the permittivity, and $\sigma$ the dc conductivity. If this occurs, then an initially hot region may be partially densified with subsequent cooling. The microwaves may then more effectively couple with a different region of the substrate. The impact of microwave-material interactions during SiC CVI is discussed in more detail in the following section. A combination of the above mentioned factors is most likely responsible for the phenomenon seen in Figure 3(b).

Figure 4 shows an end-on view of a densified fiber bundle takin from the preform center oblained using Case II CVI conditions. Also shown is the cloth total weight gain versus time data.
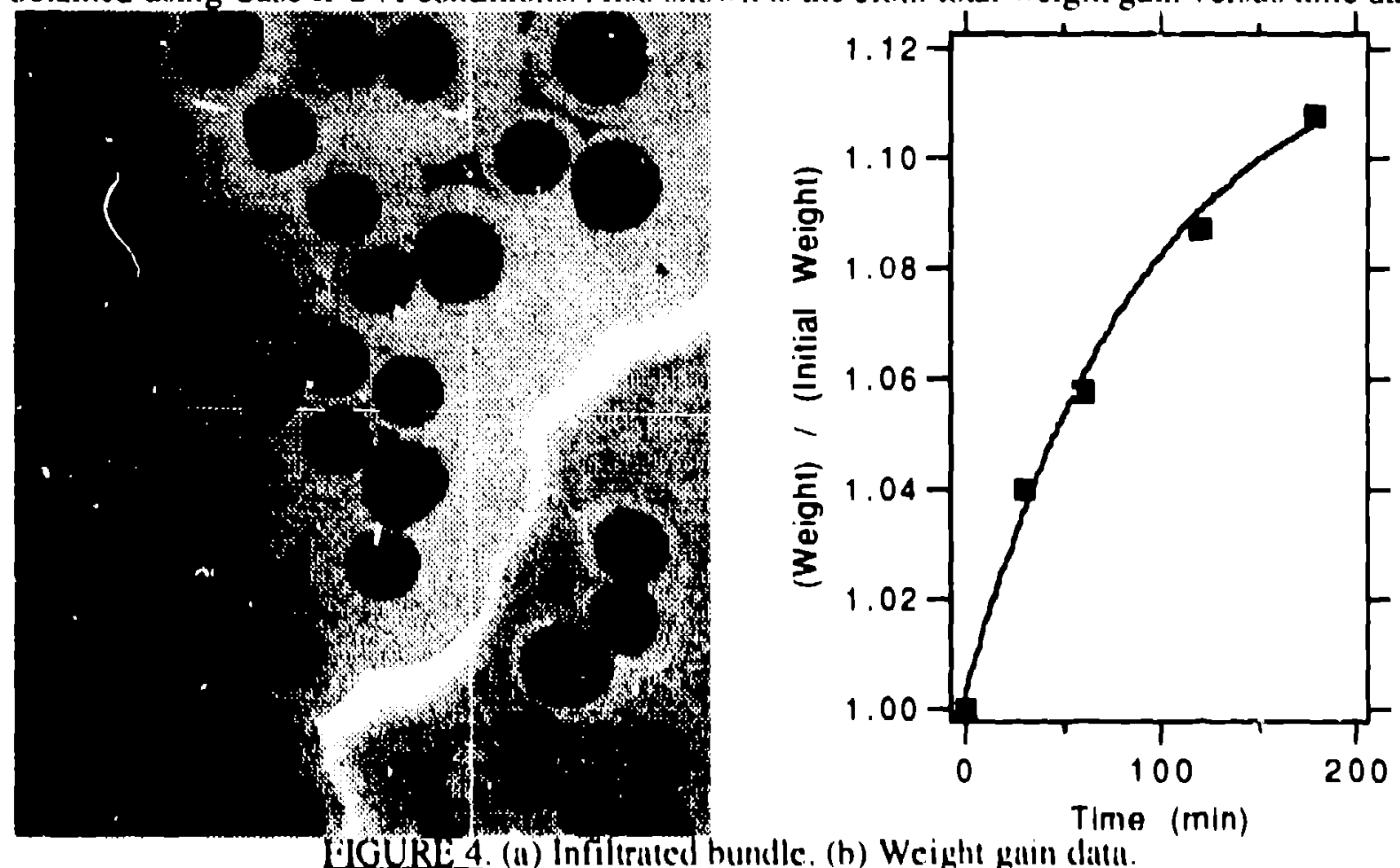
Under Case II infiltration conditions, heating patterns remained circular on a given cloth layer. The radius of the hot spot increased with time and there was no apparent cooling of the interior regions as deposition occurred. Fiber bundles in the interior of preform were reasonably dense, as seen in the fig ure. Also, the weight gain data for the stacke $d$ cloth layers showed a response typical for CVI. Howe $: r, x$-ray diffraction patterns for these samples indicated the deposit was rich in $\mathrm{Si}$. Within the densified region some zones were clearly denser than others. This again may be due to the inhomogeneous electric fields produced with the present cavity. It should be noted that the change in composition from beta-SiC to $\mathrm{SiC} / \mathrm{Si}$ resulting from changes in reactant composition and pressure is in general agreement with recent findings on the MTS- $\mathrm{H}_{2}-\mathrm{SiC}$ system [3].

\section{DISCUSSION}

Case II conditions resuited in regions of high density consisting of a SiC/Si mixture while under Case I conditions substrates were effectively extinguished after one hour of SiC deposition. Pure beta-SiC coatings of more than a few micruns could not be achieved with either set of CVI conditions. These observations suggest the coating may adversely affect absorption of microwave energy. For example, if the conductivity of the semiconducting beta-SiC coating is greater than that of the Nicalon cloth, then an increase in reflected energy from the coated surface is anticipated Reporteó room temperature conductivities for beta-SiC range from $10^{-2}$ to $10^{2}(\mathrm{ohms}-\mathrm{cm})^{-1}[4]$, with a band gap of approximately $2.0 \mathrm{eV}$. Given these values, one would expect beta $\mathrm{SiC}$ to be a good conductor at elevated temperatures. Manufacturers report the conductivity of Nicalon cloth as $10^{-3}(\mathrm{ohms}-\mathrm{cm})^{-1}$ and do not expect it to vary significantly with temperature. Considering the difference in properties between the fiber and and the coating, a drop in temperature is reasonable. It is interesting to note that with Case I conditions, the initial heating occurs in the preform center for several minutes, a time sufficient to deposit on the order of a micron of SiC. With subsequent heating, the hot zone spreads radially and visually dulls. This condition persists for an additional 15 minutes and again the hot region dulls and heating is observed only at the outer edges of the preform. It would appear that each time a critical coating thickness is reached, a new set of modes is established and therefore a different heating pattem occurs. Eventually no glow is observed and deposition ceases. For Case II however, deposition of both SiC and Si occurred with no apparent decrease in temperature. For these conditions, namely, a temperature of approximately $1(x)()^{\circ} \mathrm{C}$, high pressure, and low residence time, a reduction in temperature could result in the preferential deposition of Si over SiC. The room temperature conductivity for silicon is on the order of $10^{-5}$ $(0 \mathrm{hms}-\mathrm{cm})^{1}$, while at $1\left((2)()^{\circ} \mathrm{C}\right.$ it is approximately $1(0)(\mathrm{ohms} \mathrm{cm})^{-1}$. Presumably, the conductivity is low enough to maintain heating at a slightly reduced temperature. Figure 5 shows an interfacial

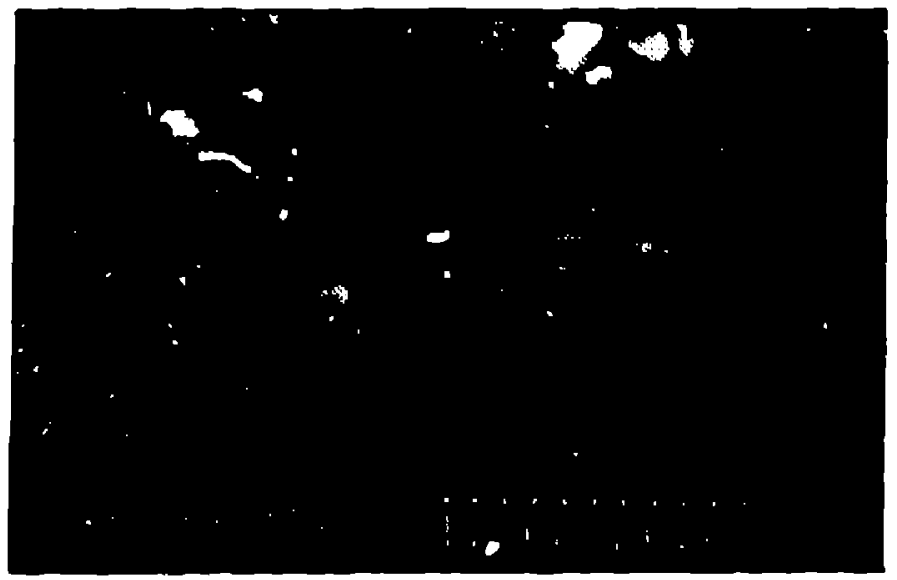

I:ICiURL: 5 , lind-on view of fiber bundle for Case II. Nole region surrounding fibers. 
layer on the order of a micron thick between the Nicalon fiber and the Si rich matrix. 'This is consistent with the idea that beta-SiC is initially deposited resulting in a subsequent decrease in temperature favoring the deposition of Si.

Initial results suggest the infiltration of beta-SiC with our present limitations on power will be difficult. It also points out the need for careful control of the matrix properties during CVI. For semiconductors, values of the conductivity in the extrinsic range can vary dramatically, covering many orders of magnitude for small variations in impurity concentration. Fortunately the CVD technique is well suited for control of these factors. The possibilities of doping and co-deposition of suitable phases to alter the conductivity and dielectric properties of the matrix material needs to be explored. This of course is only possible to the extent that it does not degrade the required mechanical properties of the composite. The effect of interfacial layers, such as carbon or boron nitride which are used to enhance the composite toughness, on subsequent microwave heating of the f:bers also needs to be explored.

For future experiments, consideration should be given to both single and multimode microwave cavities. Multimode cavities are inexpensive and easy to operate. Given a uniform ele 2 tric field and control of substrate cooling, multi-mode cavities should be capable of promoting inverted gradients in complex shaped substrates. In contrast, a single mode cavity involves regions of high field concentration and localized hot-spots. The single mode caviry is usually more energy efficient and can localize heating. However, using a single mode cavity during densification of complex shaped substrates by CVI will likely require continuous and non-trivial tuning schedules and power modulation schemes. Of primary concern should be the ability to manipulate and control the thermal gradients, which in turn govern the densification process. For exariple, it the localized heating shown in Figure 3(a) is such that the hot region is essentially isothermal with a steep thermal gradient at the outer edge then problems typically associated with convention CVI, such as pore blockage in the outer region, are possible under certain conditions. Flexibility can be maximized through use of in-silu diagnostics, variable input power, and cavity tuning.

Microwave radiation, in combination with sufficiently reduced pressures, will result in a glow discharge due to electrical breakdown in the vapor. Low operating pressures may be either intentionally set or be encountered during specific phases of a cyclical pulsed-pressure CVI process [5]. The presence of a discharge could have beneficial effects on CVI. For example, in systems where vapor phase reactions are involved, chemical kinetics may be substantially enhanced and new reaction pathways may become available. However, since it is not clear that a glow discharge can be maintained within porous preform:, plasma assisted CVI may involve only the infiltration of neutral species formed in the discharge. Furthermore, the power consumption involved in maintaining ihe discharge can be appreciable and thus limit the ability to heat the substrate as desired. Possible damage to both fiber integrity and fiber-matix interfaces from ion bombardment must also be considered. CVI in the presence of plow discharges will be explored in a future work.

In summary, microwave-induced inverted thermal gradients and the possibility of insideout densification by CVI have been demonstrated. Several issues central to further process development have been identified. This includes control over microwave power input, flow rates, and cavity luning. In addition, 11 appears that control over the matrix composition may prove necessary in order to maintain a suitable level of microwave heating, or conversely, to avoid a thermal runaway.

\section{REFERENCES}

1. Besmann, T.M., Sheldon, B.W., Lowden, R.A. and Stinton, D.P. Science 253: 1104 (1991).

2. Gupta, D. and Evans, J.W., J. Mater. Res, 6(4): 810 (1991).

3. Motojima, S. and Hasegawa, M., Thin Solid Films I $86: 1,39(199)$ ).

4. Pohl, R.G. in Silicon Cirbide. Alligh temperienre Semiconductor. Prox. Conf. on Silicon Carbide. O'Conner, J.R. and Smilteıs, J., Lids., p. 318, Pergamin Press. Boston, (196()).

5. Sugiyama, K. and Nakamura, T., J. Matter. Sci. Letters 6: 331 (1087). 